\title{
Measuring UHI in Puerto Rico
}

\author{
Luz E. Torres Molina, $\mathrm{PhD}^{1}$, Sara Morales ${ }^{2}$, and Fabian Carrion ${ }^{3}$ \\ ${ }^{1}$ Universidad Ana G Méndez, Puerto Rico, torresl6@uagm.edu \\ ${ }^{2}$ Universidad Ana G Méndez, Puerto Rico, smorales138@email.uagm.edu \\ ${ }^{3}$ Universidad Ana G Méndez, Puerto Rico, lcarrion32@email.uagm.edu
}

\begin{abstract}
This paper reviews some of the characteristics of urban climates and the causes and effects of urban heat island (UHI) issues in the tropical climate. UHI effect is a kind of heat accumulation phenomenon within the urban areas due to urban construction and human activities. It is recognized as the most evident characteristic of urban climate. The increase of land surface temperature in San Juan, Puerto Rico caused by the UHI effect was influenced by the change of land use and material types in construction. The impacts of daily temperature, surface albedo, evapotranspiration, and anthropogenic heating on the near-surface climate are discussed. Analyzed data and field measurements indicate that increasing albedo and vegetation cover can be effective in reducing the surface and air temperatures near the ground. Some mitigation and prevention measures are proposed for the effects of UHI, such as a flash flood warning system.

Keywords-- UHI, Urban, Rural, Floods, Alert, Temperature
\end{abstract}

\section{INTRODUCTION}

UHI began to be relevant decades ago when the cities began to be megacities built without any environmental planning, and when the trees and grass change to concrete and asphalt. According to the United States Environmental Protection Agency, an Urban Heat Island is created in developed areas where the built surfaces absorb and retain radiation from the sun. The impacts of Urban Heat Island include increased energy consumption, higher concentration of air pollutants, increase of air temperature level and flash flood.

Temperature is the most significant atmospheric parameter in researches about the effects of the heat island. Studies have documented that urban areas have air and surface temperatures that are, on average, $1.8-5.4^{\circ} \mathrm{F}$ higher than temperatures in surrounding rural areas, and there is potential for up to a $22^{\circ} \mathrm{F}$ difference in more extreme situations [1].

According to the NOAA's National Centers for Environmental Information (NCEI) average annual temperature for Puerto Rico and U.S Virgin Islands has increased by more than $1.5^{\circ} \mathrm{F}$ since 1950 . Under a higher emissions pathway, historically unprecedented warming is projected by the end of the $21^{\text {st }}$ century, including increases in extreme heat events and increases in flash floods.

The 2009 U.S. Global Change Research Program report entitled global climate change impacts in the U.S. illustrated that the average mainland U.S. temperature has increased by $1.1^{\circ} \mathrm{C}\left(2^{\circ} \mathrm{F}\right)$ since about 1960 , precipitation has increased by

Digital Object Identifier (DOI):

http://dx.doi.org/10.18687/LACCEI2020.1.1.47

ISBN: 978-958-52071-4-1 ISSN: 2414-6390
$5 \%$, and the frequency of heavy precipitation has also increased by a factor of two. [2]

Another important aspect to be studied is the evapotranspiration because the increase of impervious surfaces prevent the movement of air and water which are key in the cooling processes of evaporation and transpiration; and create a typical 'heat urban islands' of warmer temperatures while the green vegetation in the surrounding rural areas better regulate surface temperatures.

This research is focused on finding the typical characteristics of a city that develops UHI conditions. The cities studied are San Juan and Gurabo located in Puerto Rico northeastern, with just 20 miles away each one. Puerto Rico strategically located in the Caribbean Sea where it is exposed to atmospheric phenomena typical of climate change, from extreme droughts, flash floods, rising sea levels, major hurricanes and earthquakes. Figure 1.

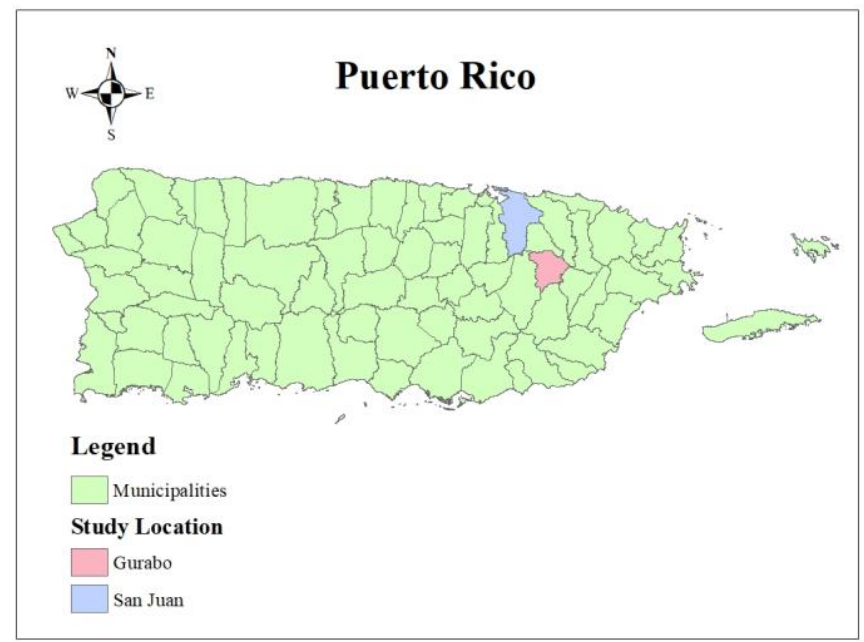

Fig. 1 Study Location.

The flash flood is a consequence of Urban Heat Island. Most people consider that sudden floods are the product of weather phenomena such as tropical waves trough even hurricanes. Previous studies have shown that most of flash floods are caused by anthropogenic behavior generally named anthropogenic heat; which is generated by human activity and comes from many sources, such as buildings, industrial processes, change in the land use from pervious to impervious. 


\section{LOCAL CLIMATE}

The climate of the Caribbean is characterized as subtropical with relatively dry winters and wet summers [3]. The dominant large-scale atmospheric influence on the climate is the North Atlantic subtropical high (NAH). The average temperature at the San Juan, Puerto Rico station, last year was $80.74^{\circ} \mathrm{F}$. Figure 2 shows the annual temperature between the month considered historically coldest of the year "January", and the hottest month of the year "september" in San Juan City. Data of nineteen (19) years were taken for this analysis (National Weather Service, 2019) [4]. The data reflects a tendency to increase year after year.

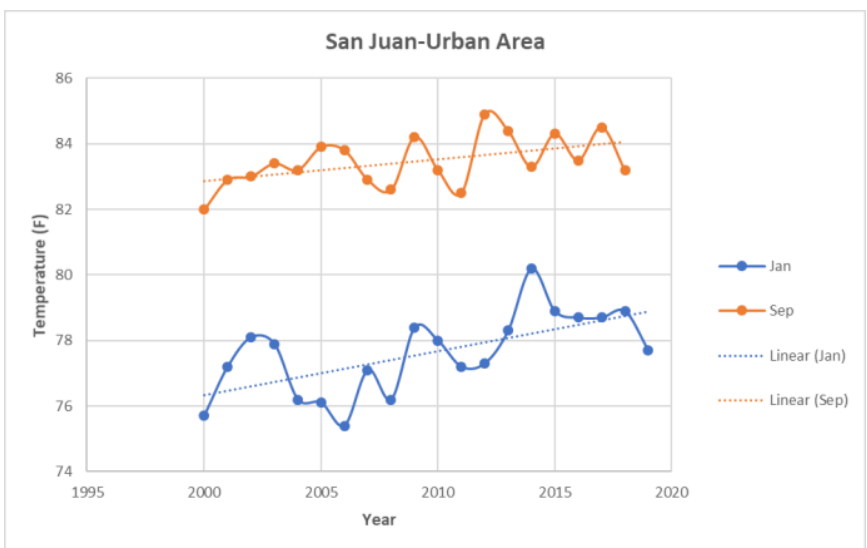

Figure. 2 San Juan, Puerto Rico annual temperature $\left({ }^{\circ} \mathrm{F}\right)$ 2000-2019

\section{STUDY LOCATION}

The study UHI is based on the premise that significantly warmer surface temperatures exist in urban settings as opposed to their surrounding rural areas. To make sure that this premise is correct for the Puerto Rico case, seven locations have been selected, which cover the island (Figure $3)$.

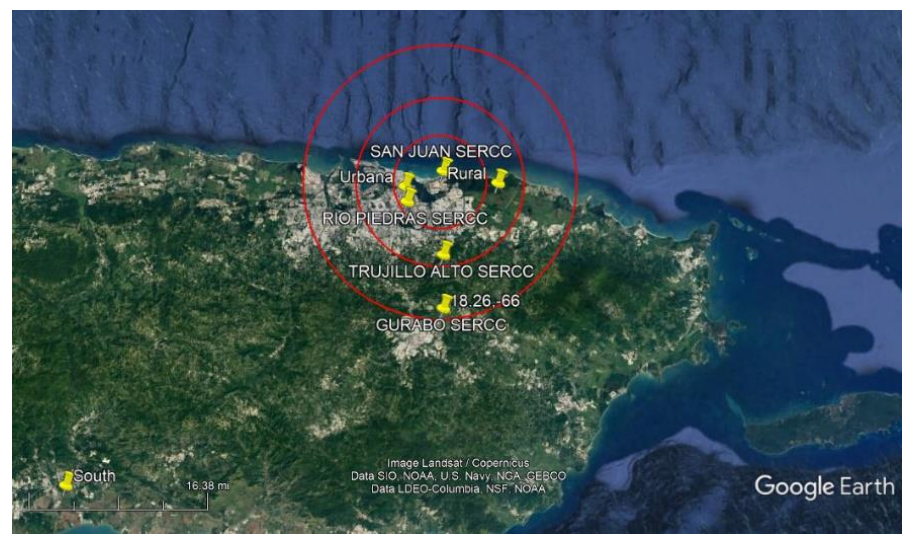

Figure. 3 Study locations, Puerto Rico.
For this research the main parameter to consider in the problem definition is temperature. Data with more than five decades were used to study the changes in temperature between the urban area and the rural area. San Juan, the capital of Puerto Rico Island is considered an urban area, due to the increase in the homes and buildings construction as well as its large population. Although the population decreases over the years, its average surface temperature continues to increase. The number of residents in the city decrease from 428,800 in 1957 to 321,000 in 2019.

On the other hand, the city designated as a rural area is Gurabo, Puerto Rico. It is located at $20 \mathrm{~km}$ from San Juan. It had a population of 16,000 in 1957 , nowadays Gurabo has 46,000 residents. [5] Figure 4 shows the temperature difference between urban and rural areas. The data was taken from 1957 to 1967 in each station and display an average difference of temperature of 2.62 Fahrenheit degrees. Furthermore, the same comparative analysis was carried out for the years between 2008 and 2018 (see Figure 5). For the last year 10 years, the difference between temperature increase was around 3.46 Fahrenheit degrees.

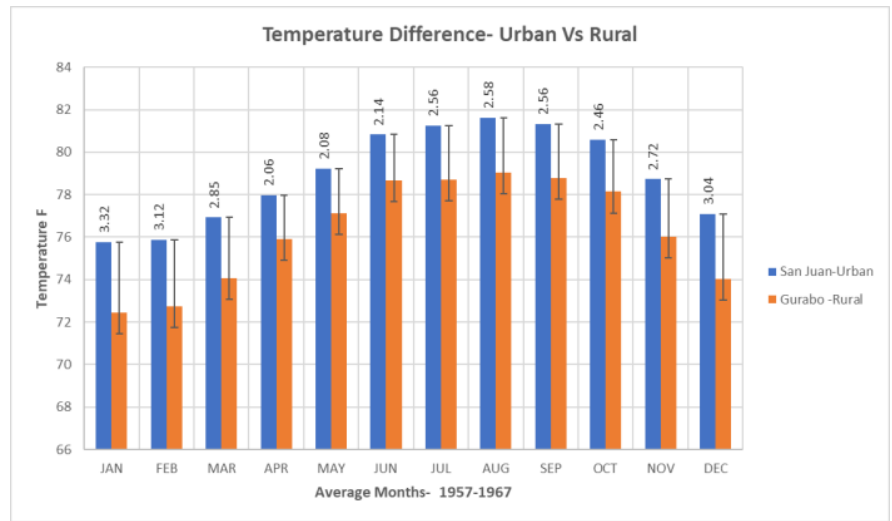

Figure. 4 Difference of temperature $\left({ }^{\circ} \mathrm{F}\right)$ between urban vs rural areas (19571967)

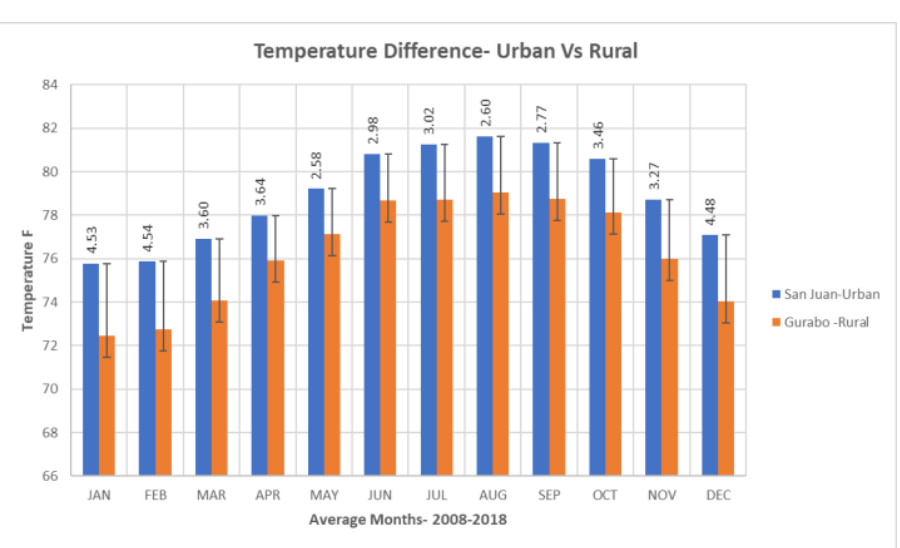

Figure. 5 Difference of temperature $\left({ }^{\circ} \mathrm{F}\right)$ between urban vs rural areas $(2008$ 2018) 
Stations located in San Juan, Puerto Rico and Gurabo, Puerto Rico show that both period 1957-1967 and period 2008-2018 temperatures are on the rise in heavily urbanized areas where there is a conversion of natural vegetation to urban dwellings.

Another way to verify the existence of heat islands is to make a parallel analysis of urban area temperature behavior as it moves away from its center and approaches a rural area. As shown in Figure 6 . the fist station away from the urban location is Rio Piedras, located at $6 \mathrm{~km}$, the next station is Trujillo Alto, at $12 \mathrm{~km}$ from San Juan, Puerto Rico and the last is Gurabo, Puerto Rico, considered as rural area located at 20 $\mathrm{km}$ from San Juan, Puerto Rico. A NASA study found that in the summer months the temperature in New York was on average $6\left({ }^{\circ} \mathrm{F}\right)$ higher than in the surrounding area.

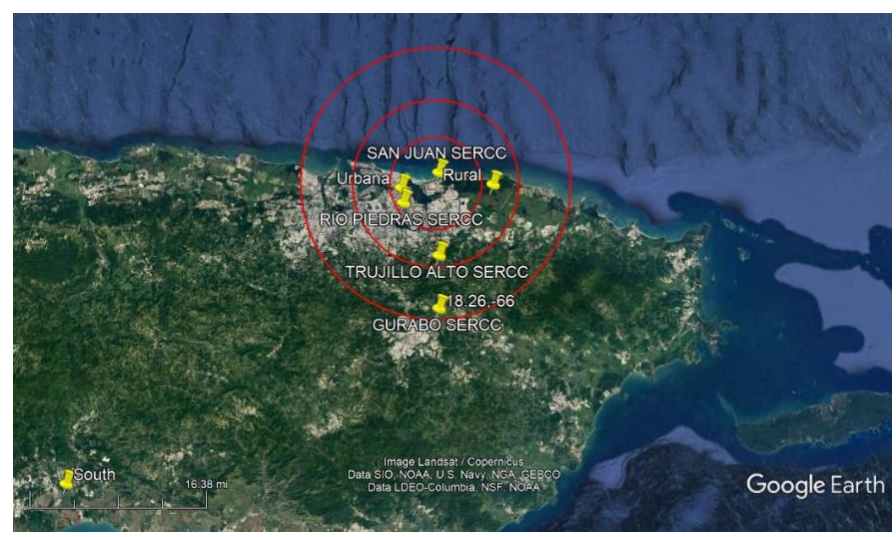

Figure. 6 Location stations San Juan- Rio Piedras - Trujillo Alto and Gurabo, Puerto Rico.

Studying the climate in Puerto Rico is very important because it is in the tropics. The countries in the tropical climate are occupying approximately 40 percent of the land surface of the earth, the tropics are the home to almost half of the world's population and supports more lives and economic activities in the region. The first and most straightforward negative impact of tropical climate is its relatively high temperature and relative humidity, which may cause thermal discomfort and make the tempo of life slower in the region.

The region between $15^{\circ}$ to $35^{\circ}$ latitude north and south is where the greatest amount of solar radiation is received, Puerto Rico located in the latitude 18, optimum to receive a great proportion of diffused radiation due to high humidity and the cloud cover in the region.

Considering the temperature average during the last 55 years in the urban area San Juan, Rio Piedras, Trujillo alto and Gurabo Puerto Rico. San Juan shows the highest values compared to the other stations, during the 12 months of the year, even with temperatures higher than Río Piedras nowadays considered part of San Juan due to urban expansion, where suburban areas become urban. Also, it is observed the tendency that the coldest months during the period studied are the months of January and February and those with the highest temperatures are august and September. The latter match with the peak of the hurricane season, where the temperature on the surface of the Atlantic Ocean is at its highest and optimum level for the formation of more powerful hurricanes. (Figure 7).

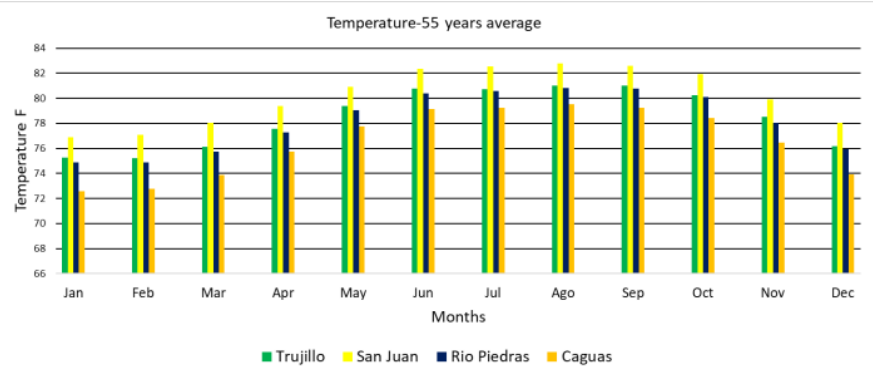

Figure. 7 Average temperature $\left({ }^{\circ} \mathrm{F}\right)$ using data of 55 years in 4 stations

Other analyses of temperature found warming in the San Juan, Puerto Rico area, with a trend of $0.09 \% / y r$ from 1957 2012. This result was obtained using the temperature data of fifty-five years ago. Figure 8 shows the projection for the month warmer September, it is observed that, although there is a difference in some years, after each decade this projection must be more accurate.

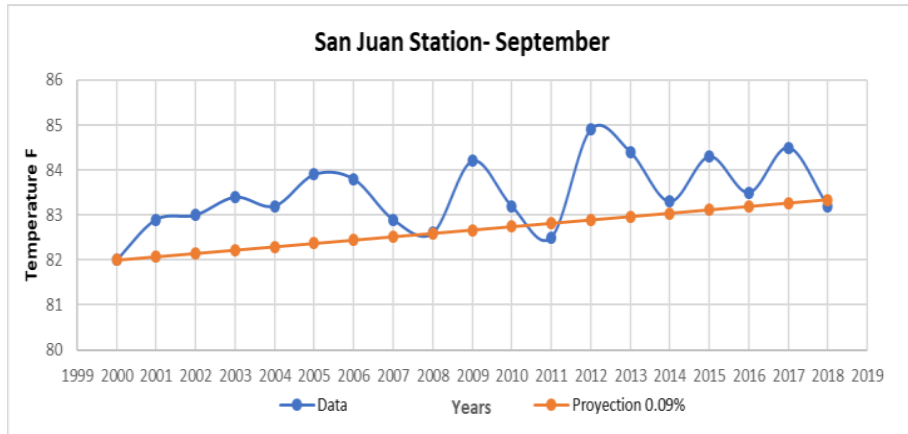

Figure. 8 San Juan temperature real data and projection $\left({ }^{\circ} \mathrm{F}\right)$

Rosenweig et al. (2006) analyzed the New York city heat island effect model by taking six case study areas and tested the mitigation strategies. They found that vegetation helps to keep surfaces cool more effectively than increasing the albedo. But they suggested that in order to reduce the temperature in New York city, replacement of low albedo materials with high albedo light-colored materials will work great as $64 \%$ of the surface area of the city can be replaced easily [6]. 
Sailor (2006) describe that the urban heat island effect mitigation can be done in two ways. One is by increasing the albedo of the urban surface and the other is by increasing evapotranspiration. On the other hand, white materials which have albedo greater than 0.60 instead of black materials having albedo of 0.05 to 0.10 can be used as roofing materials, they found that the roof temperature dropped by $25^{\circ} \mathrm{C}$ for 0.60 albedo compared to that of 0.20 albedo. More solar radiation could be reflected if the road and highway pavements were of high albedo materials. white cement mixtures can be made for which the albedo should be higher than the most reflective gray cement mixtures. However, use of high albedo materials for roads and highway pavement may not be so much effective because of the skyview factor. Even if, it is used, some of the reflection will be intercepted by the buildings surrounding it [7].

\section{EVAPOTRANSPIRATION AND NET RADIATION}

Some of the characteristics can be sorted into the four main causes of heat island formation: reduced evapotranspiration increased heat storage, increased net radiation and increased anthropogenic heat.

Lack of vegetation and increase of surface impervious cause a reduction in the evapotranspiration. Low solar reflectance and increased levels of air pollution foment increases in net radiation. Evapotranspiration is energy transmitted away from the Earth's surface by water vapor and this is a process plants use to keep cool and it increases when there is more moisture available. On the other hand, net radiation encompasses four separate radiation processes taking place at the Earth's surface. Net radiation $=$ Incoming solar - Reflected solar + Atmospheric radiation - Surface radiation. The first term in the equation is related with the amount of energy radiating from the sun. This varies according in Puerto Rico mainly with the time of day, the amount of cloud cover and the atmospheric pollution levels. The second term reflected solar is directly related with the "albedo", which is the amount of solar energy that bounces off a surface. With higher albedo, the greater the amount of reflected energy. The third term is heat emitted by particles in the atmosphere, such as clouds, pollution and Sahara dust and the last term surface radiation is heat radiated from a surface itself. A relatively warmer surface radiates more energy to its surroundings, this last is the case of San Juan city north Puerto Rico area. In 2002, the north area city had approximately $70 \%$ impervious surfaces cover, $13 \%$ grass area and $16 \%$ tress surfaces [8].

Meanwhile, solar heat absorbed by buildings during the daytime and emitted in the form of longwave radiation at night is also a major concern in cities where the urban heat island (UHI) effect can be produced by such heat being emitted from densely placed buildings.
A comparative study for evapotranspiration and net radiation was successfully accomplished, as part of the evidence to determine the heat island effect, using GOES satellite data, the ground level, $1 \mathrm{~km}$ resolution net radiation, evapotranspiration and rainfall parameters became available in Puerto Rico in march 2009 [9]. The next Figure 9 shows that during the last 10 years, evapotranspiration measures have been higher in the area designated as rural, the difference between rural and urban is very significant, and this evidences a tendency to a separation that increases with time.

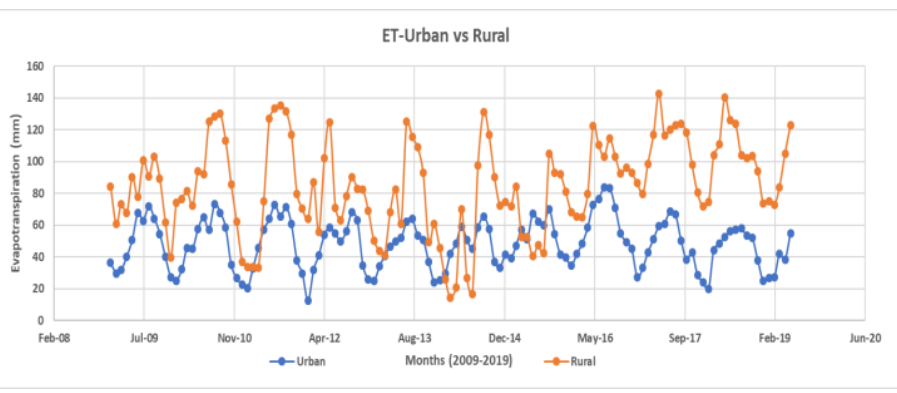

Figure. 9 Evapotranspiration (mm) urban vs rural area (2009-2019)

Net radiation collected by an urban setting is generally greater than that collected in a rural area. The difference is due to many factors, for the Puerto Rico case, exists lower solar reflectance of urban materials and restrictive urban geometries. Another significant factor, even though it occasionally happens, is the pollutant due to the Sahara dust. However, the difference in net radiation between urban and rural areas is not significant. A possible little difference is observed in Figure 10 where the urban area has higher values. During the 10 years of study, an average of $0.6656 \mathrm{MJ} / \mathrm{m} 2 / \mathrm{day}$ represents the difference in net radiation. Excessive solar radiation in San Juan area can affect the thermal conditions of buildings in two principle ways. The direct way is through openings of buildings which may heat up the interior surfaces and absorption by building façades and eventually transferred into interior space through conduction is the indirect way which can also increase heating effects indoors.

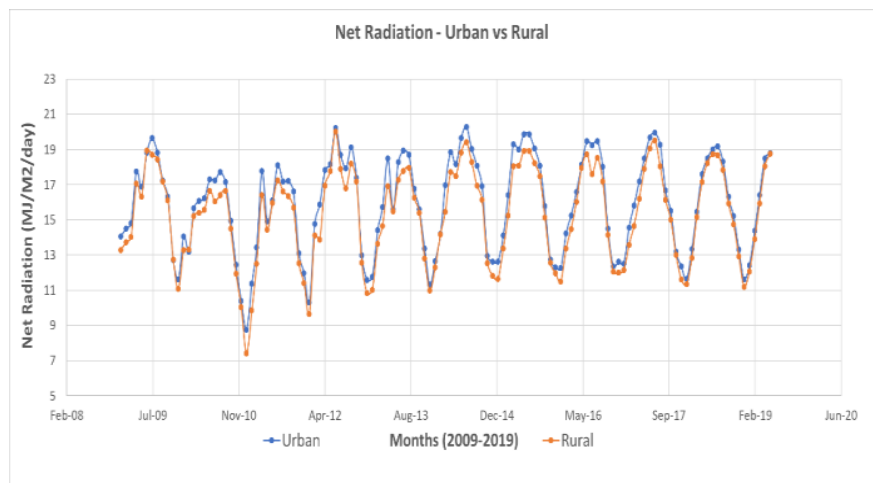

Figure. 10 Net radiation urban vs rural area (2009-2019) 


\section{SURFACES AND MATERIALS}

Buildings' volume, orientation and the aspect ratio of the spaces between them affect the exposure of urban surfaces to the solar radiation. The concentration of concrete structures without green surfaces between them increases the air temperature of urban areas. In this case study, the concentration of buildings is significantly higher in San Juan than in Gurabo, Puerto Rico (see Figure 11). The grey plots perform the building in each city. At first glance, it is observed that there is a greater amount of building structures in the city of San Juan. The city of San Juan has 3 times more building structures than the city of Gurabo. The city of San Juan has $127.98 \mathrm{~km} 2$ of the surface area of which $15.89 \mathrm{~km} 2$ are of building structures. On the other hand, the city of Gurabo has $73.22 \mathrm{~km} 2$ of which $3.33 \mathrm{~km} 2$ area of buildings.

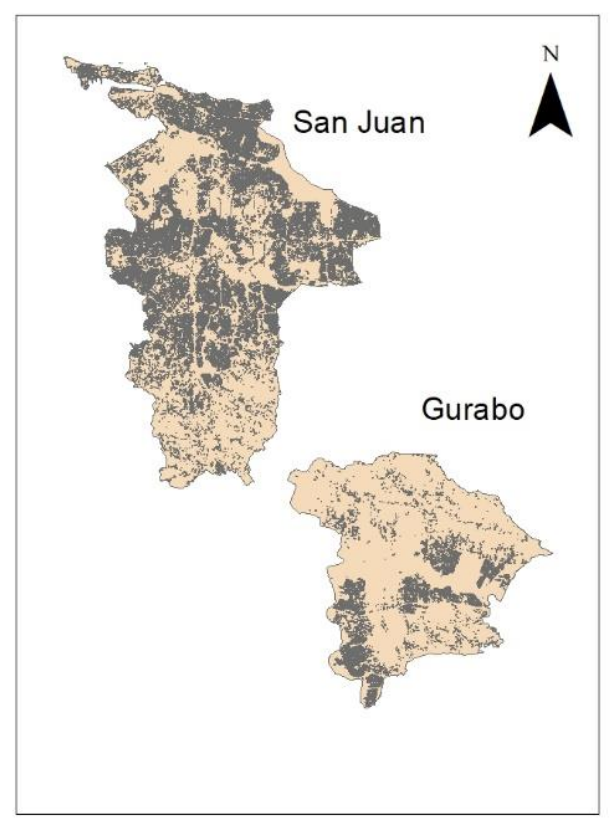

Figure. 11 Building structures San Juan vs Gurabo, Puerto Rico.

Some construction materials have properties that tend to exacerbate the heat island problem. Two material properties are important to heat storage: thermal conductivity and heat capacity. Materials with high thermal conductivity tend to conduct heat into their depths. Materials with high heat capacity can store more heat in their volume. A combination of these properties, called thermal diffusivity, is an important indicator of how easily heat can penetrate a material. Thermal diffusivity is found by dividing a material's thermal conductivity by its heat capacity. Rural areas tend to be composed of materials of lower thermal diffusivity, while urban areas have higher diffusivities. This enhances the storage of heat during the day and its slow release at night [10].

Another significant material characteristic is the albedo. Urban areas are considered with a low albedo, while rural areas are considered with higher albedos. Most urban materials reflect less incoming solar energy than materials commonly found in rural areas. Figure 12 shows differences of temperature between two widely used materials in Puerto Rico, such as asphalt and concrete at 14:00 hours of a spring day.

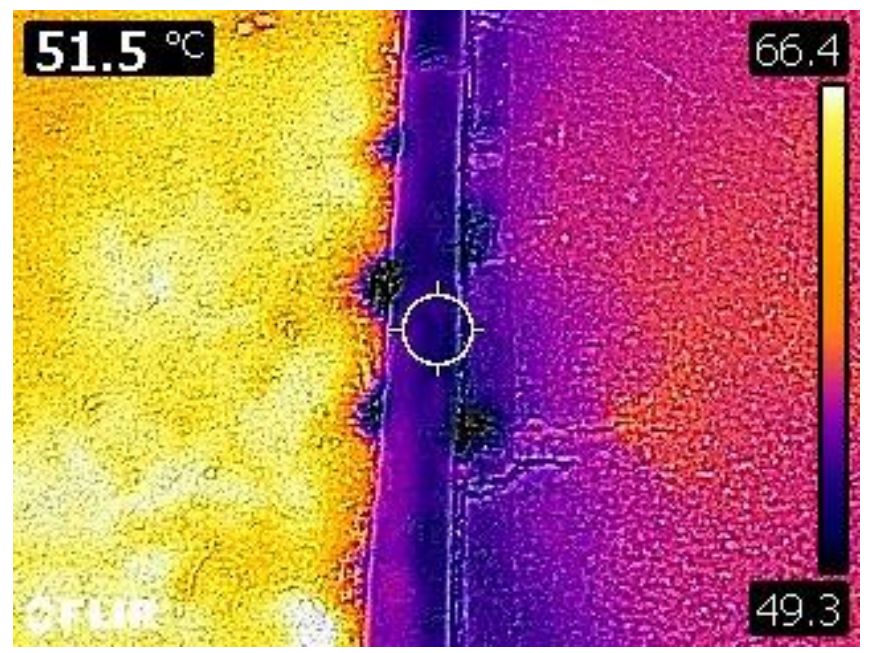

Figure. 12 Asphalt (left) vs Concrete (right) May temperatures $\left({ }^{\circ} \mathrm{C}\right)$

The asphalt shows temperatures that reach 61 fahrenheit degrees; compared to the temperature of the concrete that decreases by almost 20 degrees $\left({ }^{\circ} \mathrm{C}\right)$. This demonstrates that under normal conditions, in a country like Puerto Rico where the solar radiation received throughout the year is constantly high, the roads built on asphalt should be changed to another material such as concrete, where heat emissions decrease considerably.

Commonly in urbanized places, two prominent materials have low values of solar reflectance: asphalt paving and builtup roofing (black roofs). The prevalent use of these materials lowers the overall solar reflectance of communities. Some of the characteristics of the materials commonly found in urban and rural areas are presented in Table 1, where the specific heat capacity and albedo are important features when reference is made to UHI.

Table I

Materials characteristics

\begin{tabular}{|c|c|c|}
\hline Material & $\begin{array}{c}\text { Thermal diffusivity } \\
\left(\mathrm{mm}^{2} / \mathrm{s}\right)\end{array}$ & Albedo \\
\hline Asphalt & 1.017 & 0.04 \\
\hline Concrete & 0.677 & $0.22-0.55$ \\
\hline Wood & 0.26 & 0.15 \\
\hline Grass & - & 0.25 \\
\hline
\end{tabular}


During the winter months, the trend is preserved, figure 13 was taken in February considered the coldest month of Puerto Rico, the asphalt continues to maintain its temperature levels well above the temperature emitted by the concrete, for this case, the difference in temperature of the materials was around 10 degrees $\left({ }^{\circ} \mathrm{C}\right)$.

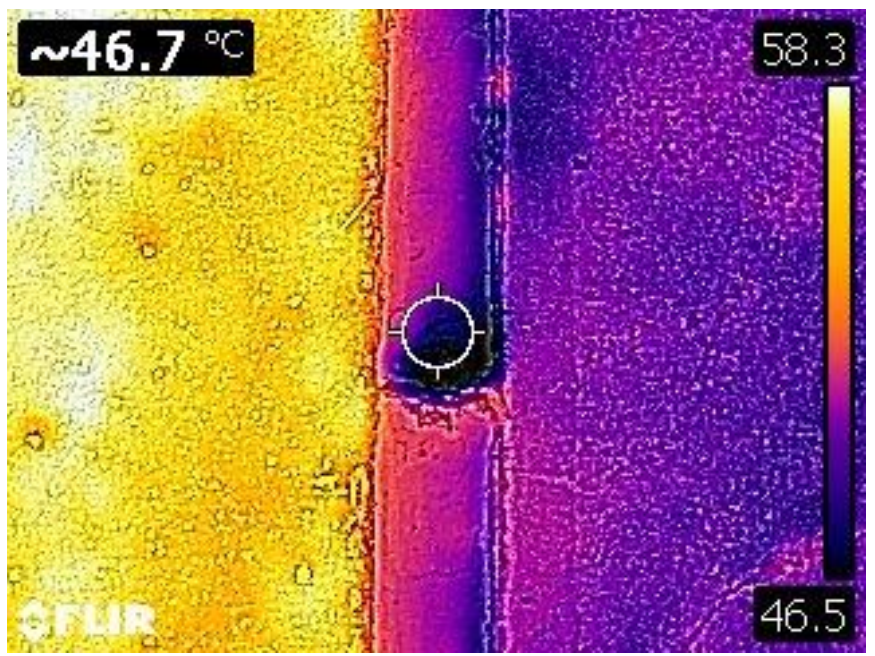

Figure. 13 Asphalt (left) vs Concrete (right) February temperatures $\left({ }^{\circ} \mathrm{C}\right)$

Some of the characteristics of cities with UHI effects are the increase in impervious areas, where land use, such as natural, grass or trees, has been changed to parking lots and roads. These changes have increased flash floods in cities, leading to major economic disasters and human losses. A personal flood alert system is being proposed as a mitigation method for this type of event.

\section{FLOODING AREAS}

Floods are the most frequent disaster type and cause more humanitarian needs than other natural disasters. One of the effects of the UHI is the flash floods, there was a consequence of the increase of the impervious areas. The use of new technologies with higher accuracy and covering areas missed by the radars, are important for flood warning systems efforts, and for studying and predicting atmospheric phenomena [11]. Almost $90 \%$ of all-natural disasters in the United States lead to flooding and $20 \%$ of all flooding claims happen in low to moderate flood risk areas [12].

This information is important when judging where to live. Home insurance doesn't cover anything that isn't attached to the house. Insurance policies for cars for example that are the most affected by flooding since most of them are outside must have specific insurance called comprehensive insurance. This system not only can save a family's pocket and vehicle, but it can also save lives by notifying them of the flash flood occurring in the area. In addition, it can help gather information about the flood in the area of the disaster.

An island such as Puerto Rico whose area is $13800 \mathrm{~km}^{2}$, where $1488 \mathrm{~km}^{2}$ are prone to flooding with a recurrence period of 100 years. About $11 \%$ of the Puerto Rico total area will enable major flooding, Figure 14.

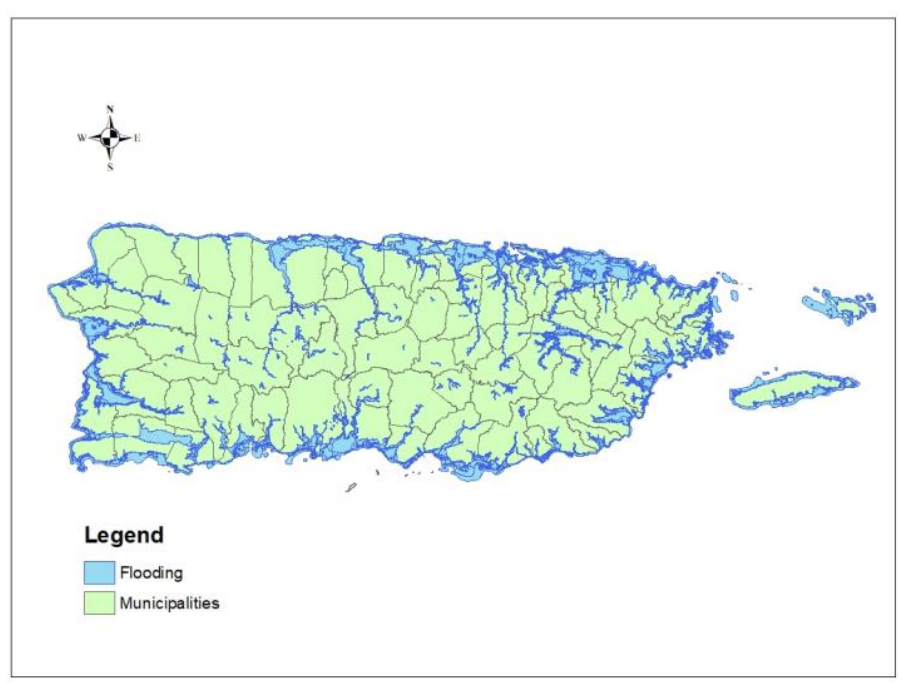

Figure. 14 Puerto Rico probability 100 years of flooding

Unfortunately, the worst flood disasters in Puerto Rico have not been due to major events. Contrarily, many of these events don't reach a recurrence period of 5 years. As was the case of precipitation that occurred on September 19, 2011, in a parking lot located in Puerto Rico western area. A Precipitation of 110 minutes caused great damage to many vehicles and floods in a significant number of storehouses in Mayaguez city. Figure 15.

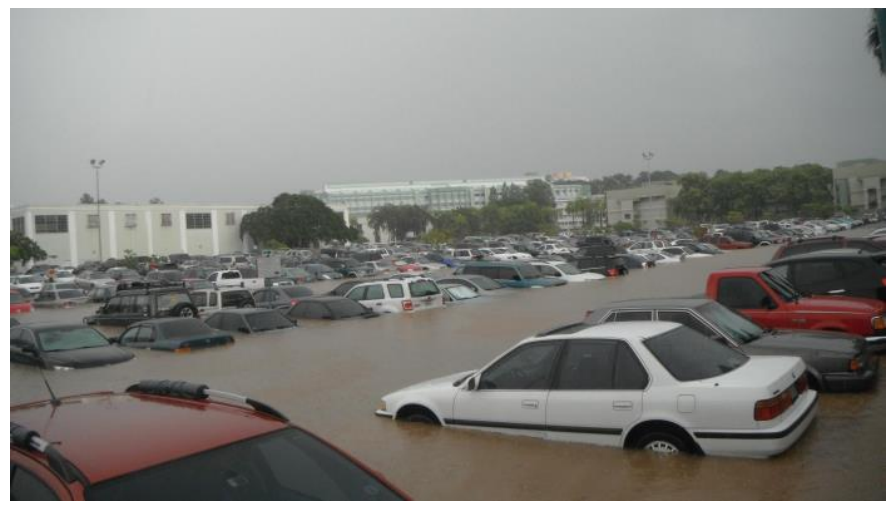

Figure. 15 Puerto Rico flooding parking lot September 19, 2011

During this brief event, it was thought that the precipitation had an average recurrence interval of 100 years. Rain gauges located in the area, display the event magnitude, 
where the maximum precipitation was of 2.65 inches behaving such as precipitation with an average recurrence interval of 5 years according to Hydrometeorological Design Studies Center NOAA's National Weather Service. This demonstrates the lack of planning when urban centers become so widespread that rural areas become urban centers, turning many areas into impervious and transforming the drainages to deficient.

Because of the unplanned growth of urban centers and poor drainage, many people lose their vehicles due to flash floods in parking lots. A way to avoid such disasters is by creating a flood alarm system that detects floods level from their own cars making this alert more specific and depend on individual case. The system must be able to do the following: detect and measure a water elevation considering the type of vehicle and its size. The alarm will function via phone call or text. As an alternative method, if there is no signal in the area the cars alarm system will alarm the owners instead of the phone call or text. Giving security to any of these two methods to notify the affected person.

How the System works is indicated in Figure 16. Once the system detects the sudden rise in water level, it will alert the owner through text or call. As a final step the owner of the vehicle will move the car to a safer location if it is possible.

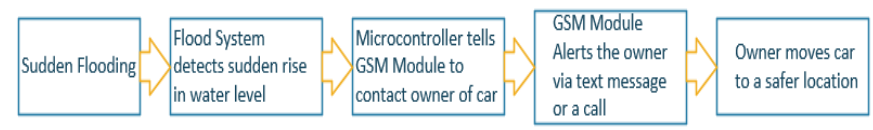

Figure. 16 Diagram of the process for a flood alert system

\section{PROPOSED SYSTEM}

The proposed system alerts the client when the water level is a threat to the vehicle. This system includes a set of sensors that will perceive different measurements in water level and vehicle acceleration. If the water level increases to a threatening level, it will alert the client via web service through a text message sending a notifies about a sudden flood every 10 seconds. When for any reason there is no signal, the system has the option to send a notification so that the vehicle horn starts to sound, this as another alternative. In case that the car is in motion it will notify the client by an audible notification. The collected data will be used to report flooded areas in real-time through a web service.

The system is located inside the car, close to each of its four tires. The Arduino will receive data from the accelerometer, ultrasonic and the GPS module. Once the data has been processed, the device will detect if the water level has risen to a threatening level. There are two form of operation, the first one when the vehicle is moving; the client will be alerted by an audible notification located inside the car. And the second one, if the vehicle is stationary; the client will receive a text message sent by the webservice. The webservice store the information received in our database and will provide information that the client may see from their devices. Figure 17 presents interaction of the system, client and webpage.

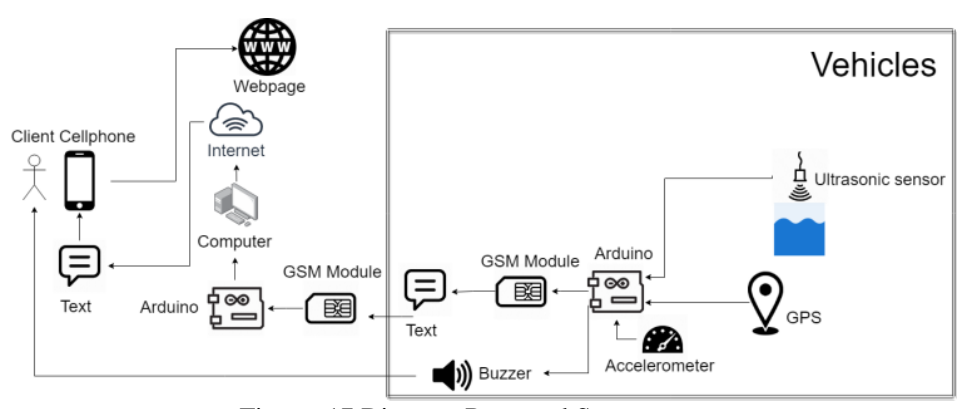

Figure. 17 Diagram Proposed System

\section{CONCLUSION}

Based on analyses of temperature, solar radiation, and flooding area it was found that the city of San Juan, Puerto Rico is the most representative zone where the UHI is present in the last 20 years. The consequences of this effect have increased more rapidly in the last 10 years. Lack of planning, uncontrolled growth of urban and residential areas, excessive use of impervious materials, using low albedo materials and dark pavement are factors that exacerbate the characteristics of UHI. To mitigate these effects and to reduce the possible consequences, the use of materials in construction and increase vegetation in urban areas should be modified. In addition to the development of a flood alert system to protect properties due to flash floods induced by the deterioration of drainage systems and poor urban planning [13]. This paper represents the first time that water level technology has been used for hydrologic analyses and specifically for these effects caused by UHI such as flash floods. The proposed system sends flood SMS alerts to the inhabitant of such zones for necessary action. The flood monitoring system can be expanded to cover a wider area than the one under study due to the protocol capabilities. In addition, this model can be used in flash floods, parking lots, streets prone to flooding and other zones with a high probability of flood.

\section{ACKNOWLEDGMENT}

Universidad Ana G Méndez - Gurabo Campus

\section{REFERENCES}

[1] EPA, 2010. Reducing Urban Heat Island.

[2] Parry ML, Canziani OF, Palutikof JP, van der Linden PJ and Hanson CE, editors. Climate Change 2007: Impacts, Adaptation and Vulnerability. Contribution of Working Group II to the Fourth Assessment Report of the Intergovernmental Panel on Climate Change. Working Group 3 Report: Society and Economy Cambridge University Press, United Kingdom; 2007. 
[3] Taylor $\mathrm{M}$ and Alfaro E. Climate of Central America and the Caribbean. In: Oliver JE, editor. Encyclopedia of World Climatology. Springer, Netherlands. 2005. p 183-189.

[4] The United States National Weather Service. Available from: http://www.weather.gov

[5] Geological maps, Department of Geology, Puerto Rico. Available from: http://www.gis.pr.gov

[6] Rosenzweig C, Solecki W and Slosberg R. Mitigating New York City's Heat Island with Urban Forestry, Living Roofs, and Light Surfaces. A Report to the New York State Energy Research and Development Authority. 2006.

[7] Sailor DJ. Mitigation of Urban Heat Islands-Recent Progress and Future Prospects. Paper Presented at the Paper presented on American Meteorological Society 6th Symposium on the Urban Environment and Forum on Managing Our Physical and Natural Resources. 2006.

[8] Ramos-González OM. The Green Areas of San Juan, Puerto Rico. Ecology and Society. 2014. 19(3): p. 21. http://dx.doi.org/10.5751/ ES-06598-190321.

[9] Puerto Rico Agricultural Water Management. Available from https://pragwater.com/

[10] Subhrajit G. A Review of Heat Islands: Understanding and Mitigating Heat in Urban Areas, Journal of the American Planning Association, 2013. 79(3): p. 256257. DOI: $10.1080 / 01944363.2013 .811377$.

[11] Torres M. Flood Alert System Using Sensor Networks in Flood Prone Zone, 2018 16th LACCEI International Multi-Conference for Engineering, Education, and Technology: Innovation in Education and Inclusion, 19-21 July 2018, Lima, Peru.

[12] Consumer Reports. Why Flooded-Out Cars Are Likely Total Losses. Available at: https://www.consumerreports.org/car-insurance/whyflooded-out-cars-are-likely-total-losses/

[13] Torres-Molina, L.E., (2014). Flood Alert system Using Rainfall Data in The Mayagüez Bay Drainage Basin, Western Puerto Rico. Doctor of Philosophy in Civil Engineering, University of Puerto Rico at Mayagüez, PR. 